\title{
CERAMBYCIDAE (COLEOPTERA) DI PUSAT PENDIDIKAN DAN KONSERVASI ALAM BODOGOL, TAMAN NASIONAL GUNUNG GEDE PANGRANGO, INDONESIA
}

\author{
Fahri $^{\left.1^{*}\right)}$, Mihwan Sataral ${ }^{2)}$, Tri Atmowidi ${ }^{3)}$, Woro A. Noerdjito ${ }^{4)}$ \\ 1) Jurusan Biologi, Fakultas MIPA, Universitas Tadulako, Palu, Sulawesi Tengah 94118 \\ 2) Jurusan Agroteknologi, Fakultas Pertanian, Universitas Tompotika, Luwuk, Sulawesi Tengah 94715 \\ ${ }^{3)}$ Departemen Biologi, Fakultas MIPA, Institut Pertanian Bogor, Kampus Darmaga, Bogor 16680 \\ 4) Bidang Zoologi, Puslit Biologi-LIPI, Cibinong, Bogor 16911 \\ *Corresponding author, e-mail: fahribadjeber11@gmail.com
}

\begin{abstract}
ABSTRAK
Penelitian ini bertujuan untuk mengetahui jenis-jenis cerambycid di Pusat Pendidikan dan Konservasi Alam Bodogol Taman Nasional Gunung Gede Pangrango. Penelitian dilaksanakan pada bulan Agustus-Oktober 2012 di tiga jalur pendakian yaitu Cipadaranten, Cikaweni dan Afrika. Di sepanjang jalur pendakian, dipasang 20 perangkap dengan jarak antar perangkap 20-30 meter. Kumbang cerambycid dikumpulkan dengan menggunakan perangkap daun dan cabang tumbuhan nangka (Artocarpus heterophyllus). Koleksi sampel dilakukan dengan menggoyang atau memukul perangkap dengan penadah di bawahnya, yang dilakukan setiap 3 hari, sampai daun perangkap rontok. Sebanyak 9 spesies dan 3 morfospesies yang terdiri dari 137 individu teridentifikasi dengan nilai keanekaragaman tertinggi $\mathrm{H}^{\prime}=2,16$ di jalur Afrika dan terendah dengan nilai $\mathrm{H}^{\prime}=$ 1,81 di jalur Cipadaranten. Nilai kemerataan tertinggi terdapat di jalur Cipadaranten E = 0,93 dan dan terendah di jalur Afrika $\mathrm{E}=0,90$. Nilai indeks Kesamaan antar jalur (indeks Bray-Curtis) tertinggi antara jalur Cipadaranten-Cikaweni IBC = 78,33 dan terendah antara jalur Cipadaranten-Afrika IBC = 72, 65 .
\end{abstract}

Kata kunci: Cerambycidae, PPKA Bodogol, Gunung Gede Pangrango

\section{PENDAHULUAN}

Kumbang cerambycid merupakan kelompok kumbang yang memiliki keanekaragaman tinggi, sekitar 35.000 spesies dan 4.000 genus tersebar di dunia (Nearns 2013). Kumbang cerambycid merupakan fitofag (Ozdikmen dan Caglar 2004), berperan penting dalam proses dekomposisi (Nieto dan Alexander 2010) dan sebagai penyerbuk (Gutowski 1990; Hawkeswood dan Turner 2007). Beberapa spesies kumbang ini dikenal sebagai hama (Asogwa et al. 2009; Rhainds et al. 2002; Morillo et al. 2008; Kutywayo 2013). Keberadaan kumbang cerambycid sangat tergantung pada tumbuhan, sehingga kumbang ini dapat dijadikan sebagai indikator kondisi hutan (Baur et al. 2005; Noerdjito 2011). Penelitian mengenai kumbang cerambycid di Indonesia dilaporkan oleh banyak ahli, diantaranya
Makihara et al. (2002), Makihara dan Noerdjito (2004); Noerdjito et al. (2005), Makihara et al. (2008), Noerdjito (2008), Vitali (2010, 2011), Vitali dan Menuvandu (2010), Casadio dan Vitali (2011), Noerdjito (2011), Noerdjito (2012), Sataral et al. (2015), Fahri (2013), Fahri dan Sataral (2015), Fahri et al. (dalam review).

Pusat Pendidikan Konservasi Alam (PPKA) Bodogol merupakan wilayah konservasi yang terletak di bagian selatan Taman Nasional Gunung Gede Pangrango (TNGGP). Luas PPKA Bodogol sekitar 2.600 ha $\left(26 \mathrm{~km}^{2}\right)$ dan ketinggiannya berkisar antara 700-1.500 m dpl, curah hujan rata-rata setiap bulan yaitu berkisar $312,2 \mathrm{~mm}$. Curah hujan tertinggi pada bulan Desember yaitu $733 \mathrm{~mm}$ dengan suhu minimum rata-rata $18^{\circ} \mathrm{C}$ dan suhu maksimum rata-rata $32^{\circ} \mathrm{C}$. PPKA Bodogol didirikan pada tahun 1998, melalui konsorsium yang diprakarsai oleh 
Conservation International Indonesia, Balai Taman Nasional Gunung Gede Pangrango dan Yayasan Alam Mitra Indonesia. Kawasan ini merupakan salah satu zona pemanfaatan kawasan Taman Nasional Gunung Gede Pangrango yang diupayakan dapat berperan serta dalam konservasi keanekaragaman hayati dan memperkenalkan kekayaan alam hutan hujan tropis kepada masyarakat umum dan masyarakat sekitar kawasan (Ario et al. 2011).

Penelitian kumbang di TNGGP telah dilaporkan oleh Kahono dan Setiadi (2007) mengenai keragaman dan kelimpahan kumbang tinja scarabaeids serta distribusinya pada ketinggian yang berbeda. Namun, khusus kumbang cerambycid di TNGGP belum dilaporkan. Penelitian ini bertujuan untuk mengetahui jenis cerambycid serta menganalisis keanekaragaman dan kesamaan komunitas kumbang cerambycid di TNGGP khususnya PPKA Bodogol.

\section{BAHAN DAN CARA KERJA}

Penelitian ini dilaksanakan pada bulan Agustus-Oktober 2012 di Pusat Pendidikan dan Konservasi Alam Bodogol TNGGP. Penentuan lokasi penelitian berdasarkan jalur pendakin, yaitu jalur Cipadaranten, Afrika dan Cikaweni.

Kumbang cerambycid dikoleksi menggunakan perangkap daun dan cabang tumbuhan nangka (Artocarpus heterophyllus) sebanyak 20 cabang dengan panjang $80 \mathrm{~cm}$ yang diikat menjadi satu dan dipasang di pohon dengan tinggi 150 $\mathrm{cm}$ dari permukaan tanah (Gambar 1a) (Noerdjito 2008). Sebanyak 20 perangkap dengan jarak antar perangkap 20-30 m yang dipasang di sepanjang jalur transek. Koleksi kumbang menggunakan metode beating dengan menggunakan layar putih berukuran 100x100 cm yang dipasang di bawah perangkap (Gambar 1b). Koleksi dilakukan dengan menggoyang atau memukul perangkap pada hari ke 5, 10 dan
15 setelah pemasangan perangkap. Identifikasi dilakukan di Laboratorium Entomologi LIPI Cibinong menggunakan Makihara (1999), Makihara et al. (2002), Makihara dan Noerdjito (2004), Slipinski dan Escalona (2013), Heffern (2013), Nearns et al. dan Bezark (2015).

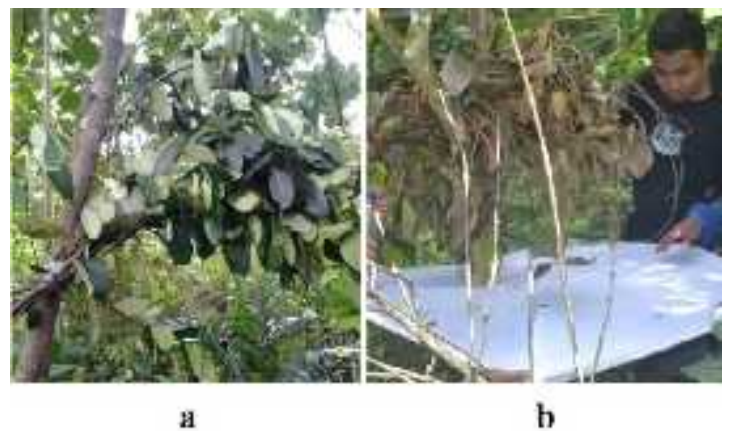

Gambar 1. Perangkap cabang tumbuhan nangka (a) dan pengumpulan spesimen kumbang dengan metode beating (b).

Koleksi kumbang cerambycid dideskripsi berdasarkan ciri-ciri morfologi dan dihitung jumlah individu (N) dan jumlah spesiesnya (S). Komunitas kumbang cerambycid dihitung menggunakan indeks keanekaragaman Shannon-Wiener $\left(\mathrm{H}^{\prime}\right)$ dan nilai kemerataan (E) (Magguran 2004). Komposisi spesies kumbang cerambycid pada setiap tipe habitat dianalisis dengan indeks kesamaan Bray-Curtis (Bray dan Curtis 1957). Data yang digunakan adalah data spesies dan kelimpahan spesies pada masing-masing habitat.

Analisis indeks keanekaragaman Shannon-Wiener, nilai kemerataan spesies dan indeks kesamaan Bray-Curtis menggunakan program Primer (Plymouth Routines in Multivariate Ecological Research) 5 for Windows. Hasil perhitungan indeks kesamaan Bray-Curtis dibuat dalam bentuk matriks yang selanjutnya digunakan untuk membuat dendogram kesamaan antar komunitas kumbang cerambycid.

\section{HASIL DAN PEMBAHASAN}

Total individu kumbang 
cerambycid dewasa yang dikoleksi dengan perangkap Artocarpus sebanyak 137 individu, yang termasuk dalam 6 tribe, 9 genus dan 12 spesies (Tabel 1). Jumlah spesies tertinggi terdapat di jalur Afrika (11 spesies), diikuti jalur Cikaweni (10 spesies), dan terendah di jalur Cipadaranten (7 spesies). Jumlah individu tertinggi di jalur Cikaweni (52 individu), diikuti jalur Afrika (43 individu), dan jalur Cipadaranten (42 individu).

Tabel 1. Jumlah spesies dan individu kumbang cerambycid yang ditemukan di jalur Cipadaranten, Cikaweni, dan Afrika

\begin{tabular}{|c|c|c|c|c|}
\hline \multirow{2}{*}{ Tribe / Spesies } & \multicolumn{3}{|c|}{ Lokasi sampling } & \multirow{2}{*}{ Jumlah } \\
\hline & Cipadaranten & Cikaweni & Afrika & \\
\hline \multicolumn{5}{|l|}{ Homonoeini } \\
\hline Trachelophora cervicollis & 3 & 7 & 2 & 12 \\
\hline \multicolumn{5}{|l|}{ Monochamini } \\
\hline Acalolepta rusticatrix & 5 & 6 & 8 & 19 \\
\hline Acalolepta sp. & - & 2 & - & 2 \\
\hline Epepeotes luscus & 3 & 4 & 7 & 14 \\
\hline Epepeotes spinosus & 6 & 2 & 5 & 13 \\
\hline \multicolumn{5}{|l|}{ Batocerini } \\
\hline Batocera sp. & - & - & 1 & 1 \\
\hline \multicolumn{5}{|l|}{ Apomecynini } \\
\hline Sybra sp. & - & - & 2 & 2 \\
\hline Ropica marmorata & - & 5 & 4 & 9 \\
\hline \multicolumn{5}{|l|}{ Nyctimeniini } \\
\hline Nyctimenius varicornis & - & 2 & 1 & 3 \\
\hline \multicolumn{5}{|l|}{ Pteropliini } \\
\hline Egesina albolineata & 4 & 3 & 1 & 8 \\
\hline Pterolophia melanura & 8 & 11 & 8 & 27 \\
\hline Pterolophia crassipes & 13 & 10 & 4 & 27 \\
\hline Jumlah individu (N) & 42 & 52 & 43 & 137 \\
\hline Jumlah spesies (S) & 7 & 10 & 11 & \\
\hline Indeks Shannon-Wiener (H') & 1,81 & 2,13 & 2,16 & \\
\hline Indeks kemerataan $(\mathrm{E})$ & 0,93 & 0,92 & 0,90 & \\
\hline
\end{tabular}

Berdasarkan indeks ShannonWiener, keanekaragaman kumbang cerambycid tertinggi berada di jalur pendakian Afrika $\left(\mathrm{H}^{\prime}=2,16\right)$ diikuti jalur pendakian Cikaweni $\left(\mathrm{H}^{\prime}=2,13\right)$ dan terendah di jalur pendakian Cipadaranten $\left(\mathrm{H}^{\prime}=1,81\right)$ (Tabel 1). Nilai kemerataan tertinggi pada jalur pendakian Cipadaranten $(E=0,93)$ diikuti pada jalur pendakian Cikaweni $(\mathrm{E}=0,92)$ dan terendah pada jalur pendakian Afrika $(\mathrm{E}=$ 0,90). Berdasarkan matriks kesamaan Bray-Curtis, nilai tertinggi $(78,334)$ antara jalur pendakian Cipadaranten-jalur pendakian Cikaweni, diikuti CikaweniAfrika 77,53, dan jalur CipadarantenAfrika (Tabel 2).

Tabel 2. Matriks kesamaan komunitas kumbang cerambycid antara jalur pendakian Cipadaranten, Cikaweni, dan Afrika

\begin{tabular}{lrcr}
\hline & Cipadaranten & Ciaweni & Afrika \\
\hline Cipadaranten & & & \\
Ciaweni & 78,33 & & \\
Afrika & 72,65 & 77,53 & \\
\hline
\end{tabular}

Perbedaan jumlah spesies dan individu kumbang cerambycid diduga karena adanya variasi tipe hutan di masingmasing jalur pendakian. Keberadaan spesies cerambycid dapat bervariasi karena perbedaan tipe hutan (Maeto et al. 2002; Oshawa 2004). Beberapa spesies yang memiliki jumlah individu tinggi yaitu Acalolepta rusticatrix, Pterolophia melanura, dan $P$. crassipes. Ketiga spesies ini memiliki wilayah distribusi yang luas. Kumbang A. rusticatrix terdistribusi di Borneo, Sumatra, Jawa, Sulawesi, Filipina, Taiwan (Heffern 2013; Fahri 2013; Fahri dan Mihwan 2015; Fahri et al. dalam review), India (Mathew et al. 2004; Mitra 2013). P. melanura terdistribusi di Borneo, Jawa, Sumatra, Malaysia, dan Vietnam (Makihara 1999; Makihara et al. 2002; Fahri 2013; Fahri et al. dalam review). P. crassipes terdistribusi di Borneo, Sumatra, Jawa, Malaysia, Filipina (Fahri 2013; Bezark 2015; Fahri et al. dalam review). 
Kumbang $A$. rusticatrix dan $P$. melanura merupakan spesies yang umum ditemukan di Jawa dan di berbagai tipe habitat (Noerdjito et al. 2009). Noerdjito (2010) melaporkan bahwa spesies $A$. rusticatrix dan $P$. melanura ditemukan dalam populasi tinggi di Kebun Raya Bogor. Tanaman yang dijadikan inang oleh kedua spesies ini juga banyak (Makihara 1999; Makihara et al. 2002). Kumbang Batocera sp. dan Sybra sp. hanya ditemukan di jalur pendakian Afrika. Kedua spesies ini diduga menempati karakter habitat yang khas.

Nilai keanekaragaman tertinggi di jalur Afrika $\left(\mathrm{H}^{\prime}=2,16\right)$, diikuti jalur Cikaweni $\left(\mathrm{H}^{\prime}=2,13\right)$ dan terendah di jalur Cipadaranten $\left(\mathrm{H}^{\prime}=1,81\right)$. Tingginya keanekaragaman di jalur pendakian Afrika diduga karena ketersediaan sumber makanan yang melimpah. Jalur pendakian Afrika didominasi oleh pohon Afrika (Maesopsis eminii). Selain itu, spesies tumbuhan bawah di lokasi ini lebih banyak dibandingkan dengan jalur pendakian Cikaweni dan Cipadaranten (pengamatan pribadi), sehingga ketersedian sumber makanan termasuk kayu yang sedang melapuk juga melimpah.

Ketersediaan makanan disuatu habitat dan tahap perkembangan dapat mempengaruhi distribusi kumbang cerambycid. Kumbang cerambycid dewasa merupakan pemakan nektar, pucuk daun, dan kulit kayu (Noerdjito 2011) dan cenderung memilih kayu mati/yang sedang melapuk untuk proses oviposisi (Hanks 1999). Meskipun demikian, beberapa spesies kumbang cerambycid juga cenderung memilih tumbuhan hidup dan menjadi hama pada tanaman sengon seperti kumbang Xystrocera festiva (Endang dan Haneda 2010).

Nilai kemerataan tertinggi di jalur pendakian Cipadaranten $(\mathrm{E}=0,93)$ dan terendah pada jalur pendakian Afrika $(\mathrm{E}=$ 0,90). Variasi nilai kemerataan tersebut disebabkan karena pada masing-masing jalur memiliki jenis vegetasi yang berbeda dan jumlah total tangkapan di tiap jalur.
Khusus pada jalur Cipadaranten, hanya 7 spesies yang terkoleksi dari keseluruhan 12 spesies pada semua jalur. Diduga hal ini yang menyebabkan nilai kemerataan tinggi bukan karena jenis vegetasi.

Adanya kemiripan komunitas kumbang cerambycid antara jalur pendakian Cipadaranten-jalur pendakian Cikaweni diduga karena kesamaan kondisi habitat. Lantai hutan dijalur tersebut lebih terbuka dan sedikit ranting dan cabang lapuk. Selain itu, sinar matahari dapat menembus lantai hutan sekitar 25-35\% (pengamatan pribadi). Berbeda dengan jalur pendakian Afrika, lantai hutan lebih rapat dengan semak belukar yang lebat dan sinar matahari menembus lantai hutan sekitar 5-10\%.

\section{UCAPAN TERIMA KASIH}

Terima kasih kami ucapkan kepada Kepala Balai Besar Taman Nasiobal Gunung Gede Pangrango atas izin penelitian, Kepala Divisi Zoologi dan Lab. Entomologi LIPI Cibinong untuk izin preservasi dan identifikasi sampel. Terima kasih kepada Mang Ae \& Bang Elan atas bantuan untuk mengoleksi sampel di Lapangan dan Pak Sarino \& Giyanto atas bantuan preservasi sampel di Laboratorium.

\section{DAFTAR PUSTAKA}

Ario A, Supriatna J, Andayani N. 2011. Owa (Hylobates molloch Audebert 1798) di Taman Nasional Gunung Gede Pangrango. Jakarta: Conservation International.

Asogwa EU, Anikwe JC, Ndubuaku TCN, Okelana FA. 2009. Distribution and Damage Characteristics of an Emerging Insect Pest of Cashew, Plocaederus ferrugineus L. Coleoptera: Cerambycidae) in Nigeria: A Preliminary Report. Afr J Biotechnol. 8: 53-58.

Baur B, Coray A, Minoretti N, Zschokke S. 2005. Dispersal of the Endangered Flightless Beetle Dorcadion fuliginator (Coleoptera: Cerambycidae) in Spatially Realistic Landscapes. Biol Conserv. 124: 49-61.

Bezark LG. 2015. A photographic Catalog of the Cerambycidae of the New World. Version 
March

2015. (https://apps2.cdfa.ca.gov/publicApps/plant/byc idDB/)

Bray JR, Curtis JT. 1957. An Ordination of the Upland Forest Communities of Southern Wisconsin. Ecol Monogr. 27: 325-349.

Casadio CA, Vitali F. 2011. Faunistic Notes about an Entomological Survey to Kepulauan Biak, Papua (Coleoptera: Cerambycidae). Suara Serangga Papua. 5: 92-97.

Endang AH, Haneda FH. 2010. Infestation of Xystrocera festiva in Paraserianthes falcataria Plantation in East Java, Indonesia, J Trop For Sci. 22: 397-402.

Fahri. 2013. Keanekaragaman dan kelimpahan Kumbang Cerambycid (Coleoptera: Cerambycidae) pada Empat Tipe Penggunaan Lahan di Provinsi Jambi [Tesis]. Bogor: Institut Pertanian Bogor.

Fahri, Sataral M. 2015. Longhorn Beetle (Coleoptera: Cerambycidae) in Enclave Area, Lore Lindu National Park, Central Sulawesi. $e-J$ Nat Sci FMIPA UNTAD. 4: 149-157

Hanks LM. 1999. Influence of The Larval Host Plant on Reproductive Strategies of Cerambycid Beetles. Annu Rev Entomol. 44: 483-505.

Hawkeswood TJ, Turner JR. 2007. Record of Pollination of Lomatia silaifolia (Sm.) R.Br. (Proteaceae) by the Longicorn Beetle Uracanthus triangularis (Hope, 1833) (Coleoptera: Cerambycidae). Calodema. 53: 13.

Heffern DJ. 2013. A Catalog and Bibliography of Longhorned Beetles from Borneo (Coleoptera: Cerambycidae, Disteniidae and Vesperidae) [bibliography]. Elcetronic Version 2013.1.

Kahono S, Setiadi LK. 2007. Keragaman dan Distribusi Vertikal Kumbang Tinja Scarabaeids (Coleoptera: Scarabaeidae) di Hutan Tropis Basah Pegunungan Taman Nasional Gede Pangrango, Jawa Barat, Indonesia. Biodiversitas. 7: 118-122.

Kutywayo D, Chemura A, Kusena W, Chidoko P, Mahoya C. 2013. The Impact of Climate Change on The Potential Distribution of Agricultural Pests: The Case of The Coffee White Stem Borer (Monochamus leuconotus P.) in Zimbabwe. Plos One. 8: 1-11.

Maeto K, Sato S, Miyata H. 2002. Species Diversity of Longicorn Beetles in Humid Warmtemperate Forests: The Impact of Forest Management Practices on Oldgrowth Forest Species in Southwestern Japan. Biodiv Conserv. 11: 1919-1937.

Magurran AE. 2004. Measuring Biologycal Diversity. New Jersey (US): Blackwell Publishing.

Makihara H, Mannakkara A, Fujimura T, Ohtake A. 2008. Checklist of Longicorn Coleoptera of
Sri Lanka. Vesperidae and Cerambycidae Excluding Lamiinae. Bull FFPRI. 7: 95-110.

Makihara H, Noerdjito WA, Sugiharto. 2002. Longicorn Beetles from Gunung Halimun National Park, West Java, Indonesia from 19972002 (Coleoptera, Disteniidae and Cerambycidae). Bull FFPRI. 1: 189-223.

Makihara H, Noerdjito WA. 2004. Longicorn Beetles of Museum Zoologicum Bogoriense, Identified by Dr. E.F. Gilmour, 1963 (Coleoptera: Disteniidae and Cerambycidae). Bull FFPRI. : 49-98.

Makihara H. 1999. Atlas of Longicorn Beetles in Bukit Soeharto Education Forest, Mulawarman University, East Kalimantan, Indonesia. PUSREHUT Special Publication. 7:1-40.

Mathew G, Chandran R, Brijesh CM, Shamsudeen RSM. 2004. Insect Fauna of Shendurny Wildlife Sanctuary, Kerala. J Zoos Print. 19:1321-1327.

Mitra B. 2013. New Records of Longicorn Beetle Borers (Lamiinae: Cerambycidae: Coleoptera) from Little Nicobar Island, Indian Ocean. $J$ Andaman Sci Assoc. 18: 123-124.

Morillo F, Sanchez P, Giron C, Valera A, Muñoz, W, Guerra J. 2008. Behavior of Cacao Hybrids (Theobroma cacao) to Attack by Steirastoma breve (Coleoptera: Cerambycidae). Rev Colomb Entomol. 34: 151-155.

Nearns EH, Lord NP, Lingafelter SW, Santos-Silva A, Miller KB, Zaspel JM. 2015. Longicorn ID: Tool for Diagnosing Cerambycoid Families, Subfamilies, and Tribes. The University of New Mexico, Purdue University, and USDA APHIS PPQ Identification Technology Program (ITP) (http://cerambycids.com/longicornid/).

Nearns EH. 2013. Systematics of Longhorned Beetles (Insecta: Coleoptera: Cerambycidae) [Dissertation]. New Mexico: Biology Department University of New Mexico.

Nieto A, Alexander KNA. 2010. European Red List of Saproxylic Beetles. Luxembourg: European Union Pr.

Noerdjito WA, Makihara H, Matsumoto K. 2005. Longicorn Beetle Fauna (Coleoptera, Cerambycidae) Collected from Friendship Forest at Sekaroh, Lombok. Proceedings of International Workshop on the Landscape Level Rehabilitation of Degraded Tropical Forest, Tsukuba, Japan 22-23 February 2005. FFPRI. pp. 55-64.

Noerdjito WA. 2008. Struktur Komunitas Fauna Kumbang Antena Panjang (Coleoptera; Cerambycidae) di Kawasan Taman Nasional Gunung Ciremai. J Biol Indones. 4: 371-384.

Noerdjito WA, Makihara H, Sugiharto. 2009. Evaluation of Various Forest Conditions Based on Longhorn Beetles (Coleoptera: Cerambycidae) as Bioindicators in East Kalimantan. In: Fukuyama K, Oka $\mathrm{T}$ (eds). Proceedings of International seminar on CDM 
Plantation and Biodiversity, Tsubaka, Japan, 24 February 2009. FFPRI. pp: 31-39.

Noerdjito WA. 2010. Arti Kebun Raya Bogor bagi Kehidupan Kumbang Antena Panjang (Coleoptera, Cerambicidae). J Biol Indones. 6: 289-292.

Noerdjito WA. 2011. Evaluasi Kondisi Hutan Berdasarkan Keragaman Kumbang Antena Panjang (Coleoptera: Cerambycidae) di kawasan Gunung Slamet. Ber Biol. 10:521-531.

Noerdjito WA. 2012. Dampak Kegiatan Manusia terhadap Keragaman dan Pola Distribusi Kumbang Antena Panjang (Coleoptera: Cerambycidae) di Gunung Salak, Jawa Barat. $J$ Biol Indones. 8:57-69.

Ohsawa M. 2004. Species Richness of Cerambycidae in Larch Plantations and Natural Broad-Leaved Forests of The Central Mountainous Region of Japan. For Ecol Manag. 189: 375-385.

Ozdikmen H, Caglar U. 2004. Contribution to The Knowledge of Longhorned Beetles (Coleoptera, Cerambycidae) from Turkey Subfamilies Prioninae, Leturinae, Spondylidinae and Cerambycinae. J Entomol Res Soc. 6: 39-69.

Rhainds M, ChinChiew L, MoLi Z, Gries G. 2002. Incidence, Symptoms, and Intensity of Damage by Three Coffee Stemborers (Coleoptera :Cerambycidae) in South Yunan, China. J Econ Entomol. 95: 106-112.

Sataral M, Atmowidi T, Noerdjito WA. 2015. Diversity and Abundance of longhorn beetles (Coleoptera: Cerambycidae) in Gunung Walat Educational Forest, West Java, Indonesia. J Insect Biodivers. 3 (17): 1-12.

Slipinski A, Escalona HE. 2013. Australian Longhorn Beetles (Coleoptera: Cerambycidae) Volume 1, Introduction and Subfamily Lamiinae. Canberra: CSIRO Publishing.

Vitali F, Menufandu H. 2010. A New Species of Protilema Aurivillius, 1908 (Coleoptera: Cerambycidae, Morimopsini) from Waigeu Island, New Guinea. Suara Serangga Papua. 4: 89-93.

Vitali F. 2010. Taxonomic and Synonymic Notes about Some Indonesian Apecies of The Genus Acalolepta Pascoe, 1858 (Coleoptera: Cerambycidae, Lamiini). Suara Serangga Рариа. 4: 94-98.

Vitali F. 2011. Notes on the Genus Acalolepta Pascoe, 1858 (Coleoptera: Cerambycidae) from Indonesian Papua and the Moluccas. In Telnov D (ed). Biodiversity, Biogeography and Nature Conservation in Wallacea and New Guinea, Vol. I. The Entomological Society of Latvia. pp. 291-297. 